\title{
Toxic effect study of methanol extract of Terminalia glaucesens leaves following single or short-term repetitive oral administration in Swiss mice
}

\section{Tano Konan Dominique ${ }^{1}$, Kouadio James Halbin ${ }^{2, ~ *, ~ Y a v o ~ W i l l i a m ', ~ D j a m a n ~ A l i c o ~ J o s e p h ~}{ }^{3}$, Menan Eby Ignace Hervé ${ }^{1}$}

\author{
${ }^{1}$ Dept. of Parasitology-Mycology, UFR des Sciences Pharmaceutiques et Biologiques, Abidjan, Côte d'Ivoire \\ ${ }^{2}$ Dept. of Biochemistry and Microbiology, UFR Agroforesterie, University of J. Lorougnon GUEDE, Daloa, Côte d'Ivoire \\ ${ }^{3}$ Dept. of Biochemistry and Pharmacology, UFR Bioscience, University of F.H. BOIGNY, Abidjan, Côte d'Ivoire
}

\section{Email address:}

jameshalbink@yahoo.fr (J. H. Kouadio)

\section{To cite this article:}

Tanoh Konan Dominique, Kouadio James Halbin, Yavo William, Djaman Alico Joseph, Menan Eby Ignace Hervé. Toxic Effect Study of Methanol Extract of Terminalia Glaucesens Leaves Following Single or Short-Term Repetitive Oral Administration in Swiss Mice. American Journal of BioScience. Vol. 1, No. 4, 2013, pp. 85-90. doi: 10.11648/j.ajbio.20130104.16

\begin{abstract}
The uses of different parts of the plant Terminalia glaucescens in traditional medicine is well known in some African countries. Thus, the methanol or aqueous extract of plant leaves or roots was pharmacologically studied for its benefit effects in malaria, diabetes, cardiac and hepatic diseases. However, there is no investigation in probable adverse effect in order to determine safety dose for human users. In consequence, the aim of the present study was to evaluate both acute and sub-acute toxicity of methanol extract of Terminalia glaucescens leaves in Swiss mice following single oral and repetitive administration. As results, the oral LD50 of the preparation in Swiss mice was found to be greater than $2500 \mathrm{mg} / \mathrm{kg}$ body weight (bw). In the repetitive toxicity study, Swiss mice (10/sex/group) were administered via oral gavage 0 (control), 13.90 (traditional therapeutic dose for malaria) and high dose $1390 \mathrm{mg} / \mathrm{kg}$ bw/day of the plant leaves extract for 15 days. Administration of the plant leaves preparation did not result in any toxicologically significant treatment-related changes in clinical (including behavioral) observations. Interestingly, benefit effects have been observed in body weights for therapeutic dose $(13.90 \mathrm{mg} / \mathrm{kg}$ bw/day) and some organs weight such as kidney and spleen (for females) were increased. Hepatoprotection and hypolipidemic actions have been observed with serum ALT and lipids (total cholesterol and triglycerides) decrease in mice having received therapeutic dose (13.90 mg/kg bw/day). In addition, benefit effect has been observed in hemoglobin amount in animal treated by therapeutic dose. In parallel, precocious adverse effects have been observed with high dose of $1390 \mathrm{mg} / \mathrm{kg}$ bw/day in body weights and hemoglobin amounts and leukocytes cells number which were decreased when compared to control $(\mathrm{p}<0.01)$. This leucopenia was not linked to lymphocytes because they stayed unchanged. Probable neutropenia or myelotoxic effect could be the etiology of such leucopenia. Based on the results of this study, the No Observed-Adverse-Effect Level (NOAEL) for methanol extract of Terminalia glaucescens leaves in Swiss mice could be near but under $1390 \mathrm{mg} / \mathrm{kg}$ bw/ day.
\end{abstract}

Keywords: Terminalia Glaucescens-Leaves, Malaria-Therapeutic-Dose, Benefit-Effects, High-Dose-Leucopenia

\section{Introduction}

Terminalia glaucescens a plant indigenous to Africa belongs to the family Combretaceae in which the genus Terminalia comprises 135 species distributed in the tropical regions of the world [1]. Various species of the genus are used for cardiac effects, anti-atherogenic, hypolipidemic actions, hepatoprotection, and as antimicrobials [2]. T. glaucescens is prescribed as an anti-dysenteric and anti-microbial agent, and useful in the last stages of AIDS [3]. The extract of the plant showed a wide spectrum of antibacterial activity against periodontopathic bacteria [4]. The ethanolic decoction of this plant exhibited antiplasmodial activity [5], cytotoxic effects [6] and aldose reductase inhibition [7]. It is an important drug in folk medicine [8] and the parts of the plant usually used in 
African countries were leaves, barks and roots which could show various effects according to their mains chemicals bioactive compounds $[9,10]$. The Terminalia species are known to contain several triterpenes, some of which showed antifungal as well as antiviral activities [2]. The preliminary phytochemical screening of $T$ glaucescens extract revealed the presence of tannins, alkaloids, flavonoids and saponosides [11, 12]. More recently, phytochemical investigation on stem barks of $T$. glaucescens led to the isolation of a new triterpenoid glaucinoic acid along with several known compounds, arjunic acid, arjungenin, sericoside, terminalin A and friedelin [13]. Some of them showed inhibitory activity against $\beta$-glucuronidase [13], anti-inflammatory activity and lipid lowering effects and they were potent antioxidants by modulation of key antioxidant enzymes [14]. Despite these multi-various uses of $T$. glaucescens for the treatment of several diseases in African countries and activities pharmacological effects demonstrated, there is no investigation made into its toxicological effects. Thus, the aim of the present study was to explore the possible systemic toxicity of $T$ glaucescens leaves methanol extract following a single or short-term repetitive treatment of Swiss mice.

\section{Material and Methods}

\subsection{Material}

\subsubsection{Plant Material and Extract}

T. glaucescens (Combretaceae) fresh leaves were harvested from Toumodi in the Centre Province of Côte d'Ivoire. T. glaucescens was identified by Prof. Aké Assi Laurent of the Floristic Center of Abidjan and University of Felix Houphouet Boigny of Abidjan who has a long experience in the botanical study of the medicinal plants from Côte d'Ivoire. Two kilograms of the gently dried powdered leaves were macerated in a mixture of methanol-water (90:10) for seven days (with occasional stirring) at room temperature. The mixture was filtered with Whatman No.1 filter paper and lyophilized in order to obtain a dried residue which was weighted and dissolved in $0.1 \%$ dimethyl sulfoxide (DMSO) solution.

\subsubsection{Animals}

Male and female Swiss albino mice bred (7-8 week old), weighing between 20 and $25 \mathrm{~g}$ were obtained from Pasteur Institute of Côte d'Ivoire. Mice were housed in environmentally protected transparent polypropylene cages with stainless steel wire tops for a period of 1 week before induction of different treatments. The mice had free access to water. Experimental diets were placed in special containers to minimize spillage. Environmental conditions included $23-25^{\circ} \mathrm{C}$, relative humidity of $45-55 \%$, and a $12-\mathrm{h}$ light: dark cycle. The protocol for this study was approved by the Committee of Bioethics of Nangui Abrogoua University, Abidjan, Côte d'Ivoire.

\subsection{Methods}

\subsubsection{Acute Toxicity}

The acute toxicity study was based on OECD Guidelines for Testing of Chemicals (No. 420, Section 4, Health Effects). Female Swiss albino mice bred ( $1+4$ /group; 5-7 weeks of age; body weight range: 20-25 g) were administered a single oral (gavage) dose of dried residue of $T$. glaucescens leaves extract (DRL) suspended in $0.1 \%$ of DMSO at levels of 300 and $2500 \mathrm{mg} / \mathrm{kg}$ body weight. In these studies one animal was used sighting and four animals were included in the main study. In all these experiments, animals were observed for 15 days for clinical signs as well as for morbidity and mortality. On day 15 at completion, all the animals were euthanized and gross pathological examinations were undertaken.

\subsubsection{Repetitive Animal Treatment}

The sub-acute toxicity study was performed according to a protocol based on OECD Guidelines for Testing Chemicals (No. 407, Health Effects) for Repeated Dose Oral Toxicity Study in Rodents. The study was conducted in compliance with the OECD principles of Good Laboratory Practices. But, two doses of DRL were tested because of the absence of toxicity observed in acute toxicity test and high doses previously used in pharmacological studies [14]. The doses were obtained from traditional medicine uses in which the human therapeutic dose for malaria treatment in Côte d'Ivoire was evaluated at $13.9 \mathrm{mg} / \mathrm{kg}$ bw/day of DRL.

Thus, thirty mice (15 males and 15 females) were divided into three groups ( $n=10$ per group with five female + five male): (a) Normal control group (G-1), mice receiving the vehicle i.e. $0.1 \%$ DMSO; (b) Low dose (Traditional medicine therapeutic dose) group (G-2), mice receiving $13.9 \mathrm{mg} / \mathrm{kg}$ bw/day of DRL; (c) High dose (Traditional medicine human therapeutic dose $\mathrm{x}$ 100) group (G-3), mice receiving $1390 \mathrm{mg} / \mathrm{kg}$ bw/day of DRL. Each group received the appropriate vehicle $(0.1 \%$ DMSO), DRL-13.9 mg/kg bw/day or DRL-1390 mg/kg bw/day daily by oral administration for 15 days. Every day the weight of the mice was observed using a Sartorius balance (ED 224S Germany) with $0.0001 \mathrm{mg}$ accuracy and at the end of the experiment, the mice were sacrificed to collect total blood, serum and organs.

\subsubsection{Clinical Observations, Body Weights and Feed Consumption}

All animals were observed twice daily for morbidity and mortality. Clinical examinations included any abnormal clinical signs and behavioral changes over the entire observation period. The body weight and feed consumption were measured three times by week.

\subsubsection{Hematology and Clinical Chemistry}

For hematology and clinical chemistry analysis, blood samples were collected from all animals through sinus retro-orbital of animals under carbon dioxide anesthesia on 
day 16 for the three Groups (1-3). For the chemistry analysis, blood was allowed to coagulate and serum was separated after centrifugation. Hematology parameters analyzed included: hemoglobin concentration, red blood cell count, white blood cell count, lymphocytes, packed cell volume/hematocrit, mean corpuscular volume, mean corpuscular hemoglobin, platelet count, RBC distribution width by standard deviation (RDW-SD), RBC distribution width by coefficient of variation (RDW-CV), means platelet volume (MPV), platelet distribution width (PDW). Biochemical parameters analyzed included: glucose, triglycerides, total cholesterol, urea, creatinine, alkaline phosphatase (ALP), alanine aminotransferase (ALT), aspartate aminotransferase (AST), gamma-glutamyl transferase (GGT), cholinesterase, total bilirubin, uric acid, albumin, total protein, calcium, chloride, phosphorus, potassium, and sodium.

\subsubsection{Necropsy and Organ Weight}

At termination, a complete necropsy was performed on all animals. Animals were euthanized under carbon dioxide inhalation anesthesia. At the scheduled necropsies the following organs were weighed from all animals: liver, kidney, spleen, lung, and heart.

\subsection{Statistical Analyses}

The data generated by this study were statistically processed using SPSS 11.19 statistical software. The analysis of variance (ANOVA) was used to treat the data from the evaluation of hematological and biochemical parameters. Whenever a significant difference $(p<0.05)$ was revealed, the ANOVA test is complemented by the Tukey post ANOVA test to identify the variable (s) with very significant differences compared to the values of the control group.

\section{Results}

\subsection{Acute Toxicity}

In the acute toxicity study, oral LD50 of DRL in female Swiss mice was found to be greater than $2000 \mathrm{mg} / \mathrm{kg}$ body weight. The highest dose tested in these studies was 2500 $\mathrm{mg} / \mathrm{kg}$. The 15-day observation period during the acute oral toxicity study and body weight measurements did not reveal any toxic effects in either species (data not shown). Necropsy at the end of the study did not reveal any gross pathological abnormalities in animals.

\subsection{Sub-Acute Toxicity}

\subsubsection{General Observations and Body Weight}

"Fig. 1" summarized weights evolution of mice. During the study, no remarkable changes in general appearance were observed and all mice survived until scheduled necropsy. Likewise, there were no significant differences in the body weight of male mice between control and treatment animals groups. However, in females body weight significantly increased $(\mathrm{p}<0.01)$ with therapeutic dose of DRL $(13.90 \mathrm{mg} / \mathrm{kg}$ bw/day) but significantly decreased $(\mathrm{p}<0.05)$ with high therapeutic dose $\times 100$ (1390mg/kg bw/day).
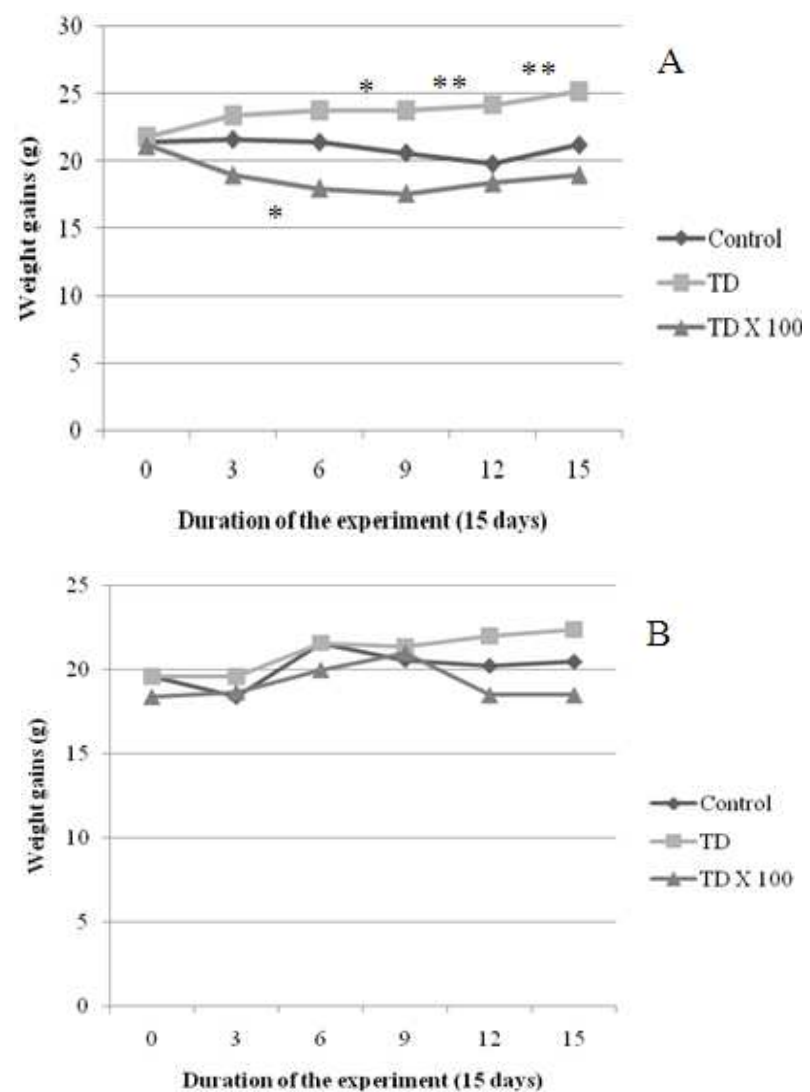

Figure 1. Weights gain after oral administration of (A) female mice and $(B)$ male mice by DRL. Significant difference explained by* $p<0.05$; ** $p<$ 0.01 .

\subsubsection{Hematological and Clinical Biochemistry}

Tables 1 and 2 showed the results of hematology. Hemoglobin level and WBC population were significantly decreased $(p<0.01)$ by DRL administration in female animals having been treated by $1390 \mathrm{mg} / \mathrm{kg}$ bw/day. A similar decrease had been observed in male at the same dose only for WBC population. However, hemoglobin level significantly increased $(\mathrm{p}<0.05)$ with therapeutic dose $(13.90 \mathrm{mg} / \mathrm{kg}$ bw/day) in both female and male mice.

For clinical biochemistry, the results summarized in table 3 revealed significant decreases in triglycerides (TG) and Total cholesterol for both female and male mice treated by DRL at different doses. In addition, ALT was decreased in female significantly at therapeutic dose $(13.90 \mathrm{mg} / \mathrm{kg}$ bw/day) but slightly at high dose of $1390 \mathrm{mg} / \mathrm{kg}$ bw/day. At least, albumin and level and calcium concentration were significantly increased $(\mathrm{p}<0.05)$ in males at dose of $1390 \mathrm{mg} / \mathrm{kg}$ bw/day and slightly at therapeutic dose only for albumin when compared to control. 
Table 1. Effect of DRL on hematological parameters in female mice.

\begin{tabular}{ccccc}
\hline Females & Units & Control & $\mathbf{1 3 . 9 0} \mathbf{~ m g} / \mathbf{k g}$ & $\mathbf{1 3 9 0} \mathbf{m g} / \mathbf{k g}$ \\
\hline WBC & $10^{3} / \mathrm{mm}^{3}$ & $9.08 \pm 0.21$ & $8.4 \pm 2.93$ & $6.67 \pm 0.7 * *$ \\
Lymphocytes & $\%$ & $88.3 \pm 4.33$ & $88.13 \pm 0.11$ & $78.8 \pm 9.38$ \\
RBC & $10^{6} / \mathrm{mm}^{3}$ & $8.86 \pm 2.27$ & $9.6 \pm 0.64$ & $8.11 \pm 0.32$ \\
Hemoglobin & $\mathrm{g} / \mathrm{dl}$ & $13.78 \pm 0.46$ & $14.72 \pm 0.47^{*}$ & $12.38 \pm 0.74^{* *}$ \\
Hematocrit & $\%$ & $40.88 \pm 2.75$ & $42.42 \pm 0.78$ & $35.88 \pm 2.33^{*}$ \\
MCV & $\mathrm{fl}$ & $44.34 \pm 1.15$ & $44.34 \pm 2.7$ & $44.28 \pm 3.38$ \\
MCH & $\mathrm{Pg}$ & $15.24 \pm 0.33$ & $15.36 \pm 0.6$ & $15.25 \pm 0.5$ \\
MCHC & $\%$ & $36.6 \pm 4.76$ & $34.74 \pm 0.86$ & $34.58 \pm 2.68$ \\
RDW-SD & $\mathrm{fl}$ & $34.46 \pm 1.85$ & $32.78 \pm 2.14$ & $32.1 \pm 5.2$ \\
RDW-CV & $\%$ & $23.26 \pm 1.41$ & $24.2 \pm 1.47$ & $22.95 \pm 1.33$ \\
Platelets & $10^{3} / \mathrm{mm}^{3}$ & $777.2 \pm 325$ & $895 \pm 201$ & $635 \pm 105$ \\
MPV & $\mathrm{fl}$ & $7.1 \pm 0.21$ & $6.82 \pm 0.41$ & $7.35 \pm 0.47$ \\
PDW & $\%$ & $8.23 \pm 0.46$ & $7.98 \pm 0.41$ & $8.93 \pm 1.36$ \\
\hline
\end{tabular}

Values are mean $\pm \mathrm{SEM}$ for 5 mice in each group. $\mathrm{RBC}=$ red blood cells; $\mathrm{WBC}=$ white blood cells; $\mathrm{PCV}=$ packed cell volume; $\mathrm{MCV}=$ mean cell volume; $\mathrm{MCH}=$ mean cell hemoglobin; $\mathrm{MCHC}=$ mean corpuscular hemoglobin concentration, RBC distribution width by standard deviation (RDW-SD), RBC distribution width by coefficient of variation (RDW-CV), means platelet volume (MPV), platelet distribution width (PDW). Significant difference explained by $* \mathrm{p}<0.05 ; * * \mathrm{p}<0.01$.

Table 2. Effect of DRL on hematological parameters in male mice.

\begin{tabular}{ccccc}
\hline Males & Units & Control & $\mathbf{1 3 . 9 0} \mathbf{~ m g} / \mathbf{k g}$ & $\mathbf{1 3 9 0} \mathbf{m g} / \mathbf{k g}$ \\
\hline WBC & $10^{3} / \mathrm{mm}^{3}$ & $10.12 \pm 3.84$ & $8.37 \pm 2$ & $3.33 \pm 0.7 * *$ \\
Lymphocytes & $\%$ & $90.5 \pm 4.08$ & $85.8 \pm 0.6$ & $85.4 \pm 0.02$ \\
RBC & $10^{6} / \mathrm{mm}^{3}$ & $8.7 \pm 1.2$ & $8.99 \pm 0.6$ & $8 \pm 0.4$ \\
Hemoglobin & $\mathrm{g} / \mathrm{dl}$ & $13.3 \pm 1.89$ & $14.38 \pm 0.74$ & $12.15 \pm 0.63$ \\
Hematocrit & $\%$ & $39.6 \pm 3.3$ & $41.92 \pm 2.04$ & $36.55 \pm 1.62$ \\
MCV & $\mathrm{fl}$ & $45.78 \pm 2.4$ & $46.77 \pm 2.52$ & $45.7 \pm 0.28$ \\
MCH & $\mathrm{Pg}$ & $15.3 \pm 0.18$ & $16.04 \pm 0.55$ & $15.2 \pm 0.11$ \\
MCHC & $\%$ & $33.45 \pm 1.92$ & $34.32 \pm 1.50$ & $33.25 \pm 0.21$ \\
RDW-SD & $\mathrm{fl}$ & $38.1 \pm 2.55$ & $37.16 \pm 2.04$ & $37.9 \pm 1.98$ \\
RDW-CV & $\%$ & $25.6 \pm 1.90$ & $24.7 \pm 0.7$ & $25.05 \pm 0.5$ \\
Platelets & $10^{3} / \mathrm{mm}^{3}$ & $1129.8 \pm 364$ & $1089 \pm 247.7$ & $777 \pm 97.6$ \\
MPV & $\mathrm{fl}$ & $7.48 \pm 0.46$ & $6.86 \pm 0.18$ & $7.1 \pm 0.42$ \\
PDW & $\%$ & $8.75 \pm 0.6$ & $8.22 \pm 0.78$ & $8.4 \pm 0.85$ \\
\hline
\end{tabular}

Values are mean \pm SEM for 5 mice in each group. $\mathrm{RBC}=$ red blood cells; $\mathrm{WBC}=$ white blood cells; $\mathrm{PCV}=$ packed cell volume; $\mathrm{MCV}=$ mean cell volume; $\mathrm{MCH}=$ mean cell hemoglobin; $\mathrm{MCHC}=$ mean corpuscular hemoglobin concentration, RBC distribution width by standard deviation (RDW-SD), RBC distribution width by coefficient of variation (RDW-CV), platelet distribution width (PDW). Significant difference explained by * $\mathrm{p}$ $<0.05 ; * * \mathrm{p}<0.01$.

\subsubsection{Organ Weights}

Table 4 summarized results of organ weights. Relative kidney weight significantly was increased only for female mice having received therapeutic dose of DRL $(13.90 \mathrm{mg} / \mathrm{kg}$ bw/day). Excepted dark color of liver observed with female and male animals having received high $1390 \mathrm{mg} / \mathrm{kg}$ bw/day, no changes were observed in other organs excepted spleen weight increasing.

Table 4. Organs relative weights after mice oral treatment by DRL at traditional therapeutic dose and its multiple of 100. *Significant difference explained by $p<0.05$.

\begin{tabular}{|c|c|c|c|c|}
\hline Organs & Sex & Control & $13.90 \mathrm{mg} / \mathrm{kg}$ & $1390 \mathrm{mg} / \mathrm{kg}$ \\
\hline Liver & $\mathrm{F}$ & $0.96 \pm 0.06$ & $1.04 \pm 0.11$ & $1.0 \pm 0.16$ \\
\hline Kidney & $\mathrm{F}$ & $0.25 \pm 0.02$ & $0.3 \pm 0.02 *$ & $0.27 \pm 0.04$ \\
\hline Heart & $\mathrm{F}$ & $0.11 \pm 0.02$ & $0.11 \pm 0.02$ & $0.11 \pm 0.03$ \\
\hline Spleen & $\mathrm{F}$ & $0.07 \pm 0.02$ & $0.06 \pm 0.01$ & $0.10 \pm 0.02 *$ \\
\hline Lung & $\mathrm{F}$ & $0.13 \pm 0.02$ & $0.17 \pm 0.03$ & $0.16 \pm 0.02$ \\
\hline Liver & M & $1.06 \pm 0.25$ & $1.04 \pm 0.09$ & $0.98 \pm 0.28$ \\
\hline Kidney & M & $0.32 \pm 0.07$ & $0.32 \pm 0.05$ & $0.26 \pm 0.06$ \\
\hline Heart & M & $0.10 \pm 0.02$ & $0.10 \pm 0.01$ & $0.08 \pm 0.02$ \\
\hline Spleen & M & $0.08 \pm 0.01$ & $0.07 \pm 0.01$ & $0.09 \pm 0.01$ \\
\hline Lung & M & $0.16 \pm 0.04$ & $0.14 \pm 0.02$ & $0.11 \pm 0.00$ \\
\hline
\end{tabular}

\section{Discussion}

Although there have been previous reports on pharmacological profile of Terminalia glaucesens leaves extracts, however, its available toxicological profiles including the NOAEL have been unexplored. It well known several biological active compounds had been found from leaves or roots extracts of $T$. glaucesens which were able to induce numerous benefit effects in malaria, obesity, diabetes, cardiac pathologies, liver pathologies and dysentery [1-7]. It had been reported these biological active compounds modulated some enyzymes activities such as $\beta$-glucuronidase, SOD, CAT, and GPx, that indicating their antioxidant properties $[13,14]$. However, in parallel to the potential health benefits recognized, it is not excluded probable adverse effects may be observed at some doses especially high doses of the plant. Thus, different doses of methanol extract of $T$. glaucesens leaves were studied at single or repetitive oral administration. For the acute toxicity, our results revealed the DL50 of the methanol extract of $T$. glaucesens leaves was higher than $2500 \mathrm{mg} / \mathrm{kg}$ bw. That indicated there is no adverse effect when considered the acute toxicity by oral administration. But, this acute result was not sufficient to conclude an absence of toxicity of $T$. glaucesens leaves. Indeed, toxicological evaluations by repeated dose studies have been generally accepted, which has been advocated as a fundamental test for safety assessment [15]. Thus, the therapeutic dose of $13.90 \mathrm{mg} / \mathrm{kg}$ bw of $T$. glaucesens leaves extracts reasonably used in traditional medicine treatment of malaria in Côte d'Ivoire and its multiple of $100(1390 \mathrm{mg} / \mathrm{kg} \mathrm{bw})$ have been oral administrated repetitively to female and male mice for 15 days in order to demonstrate NOAEL of T. glaucesens leaves used at such doses. During the study, body weights significantly increased with therapeutic dose $(13.90 \mathrm{mg} / \mathrm{kg}$ bw) but decreased with $1390 \mathrm{mg} / \mathrm{kg}$ bw in females. For 
males, similar effects on body weights have been observed but were slight. Thus, benefit effects on body weights have been observed with therapeutic dose. Indeed, after the consumption of the plant, animals showed a slight stimulation of appetite and water drinking. It is known that in addition to their therapeutic properties, medicinal plants can affect positively the nutrition of an animal [16]. The benefit effects of therapeutic dose of $T$. glaucesens leaves have been revealed by the significant increase of hemoglobin levels in both females and males. Biological actives compounds occurred in plant extract may stimulate the mechanism of hemoglobin production but not RBC cells which were unchanged during the experiment. In contrast, at high dose of $1390 \mathrm{mg} / \mathrm{kg}$ bw/day, the adverse effect seemed appear with significant decrease in hemoglobin level and WBC population $(p<0.01)$. The decrease of hemoglobin level was not link to erythrocytes level because they were stayed stable when compared to animal control. Thus, it is plausible that the adverse effect observed with high dose $(1390 \mathrm{mg} / \mathrm{kg}$ bw/day) was resulted from direct action of biological actives compounds occurred in plant leaves on hemoglobin mechanism biosynthesis. The plant preparation DRL could modulate hemoglobin level by stimulation or reduction in hemoglobin production according to the dose. This way may be explored in investigations futures. Moreover, the leucopenia observed at high dose was not caused by lymphocytes levels because they were not changed when compared to those of animal control. Probably, the leucopenia observed was due to a decrease of other leucocytes levels mainly neutrophils which are more abundant among all leucocytes. Thus, the term leukopenia is often used interchangeably with neutropenia. It may result from reduced production of white blood cells or increased utilization and destruction, or both. Infection, drugs, malignancy, megaloblastosis, hypersplenism and immunoneutropenia are responsible for most cases of neutropenia [17]. Moreover, the leucopenia observed could be also caused by bone marrow deficiency or failure or disease some organs such as liver or spleen $[18,19]$. In the present, it is the very difficult to impute such adverse effect to liver despite dark color observed because no changes have been observed in serum biochemistry markers LDH, AST and ALT. But, weight gain observed in spleen organ may be considered in futures investigations in similar to bone marrow integrity under the effect of $T$. glaucesens leaves extract. In serum biochemistry examinations, our results have demonstrated hypolipidemic actions and hepatoprotection $T$. glaucesens. All doses of plant leaves extract i.e. therapeutic dose $(13.90 \mathrm{mg} / \mathrm{kg}$ bw/day) and high dose $(1390 \mathrm{mg} / \mathrm{kg} \mathrm{bw} /$ day) leaded to significant decreases in triglycerides (TG) and Total cholesterol for both female and male mice. In addition, ALT was decreased in female significantly at therapeutic dose and slightly at high dose supporting none liver involving in leucopenia observed. Thus, the level increased of albumin could be attributed to hepatoprotection induced by the plant leaves. Calcium concentration was significantly increased in males at dose of $1390 \mathrm{mg} / \mathrm{kg}$ bw/day when compared to control. But, the levels of other electrolytes such as potassium, sodium and chloride were not changes to conclude to deficiency or failure in renal filtration. Blood calcium level increasing may be consecutive to a hyperparathyroidism i.e. abnormal function of parathyroid glands or an excessive activation of immune system as observed with leucopenia [20].

Table 3. Blood parameters of female and male mice after oral treatment by DRL at doses of 13.90 and $1390 \mathrm{mg} / \mathrm{kg} \mathrm{bw} / \mathrm{day}$ during 15 days

\begin{tabular}{|c|c|c|c|c|c|c|c|}
\hline \multirow{2}{*}{ Parameters } & \multirow{2}{*}{ Units } & \multicolumn{3}{|c|}{ Female mice } & \multicolumn{3}{|c|}{ Male mice } \\
\hline & & Control & $13.90 \mathrm{mg} / \mathrm{kg}$ & $1390 \mathrm{mg} / \mathrm{kg}$ & Control & $13.90 \mathrm{mg} / \mathrm{kg}$ & $1390 \mathrm{mg} / \mathrm{kg}$ \\
\hline Glucose & $\mathrm{mg} / \mathrm{dl}$ & $0.74 \pm 0.31$ & $0.54 \pm 0.27$ & $0.89 \pm 0.47$ & $0.69 \pm 0.28$ & $0.68 \pm 0.36$ & $0.87 \pm 0.08$ \\
\hline Total Cholesterol & $\mathrm{mg} / \mathrm{dl}$ & $0.97 \pm 0.11$ & $0.97 \pm 0.11$ & $1.05 \pm 0.03$ & $1.23 \pm 0.13$ & $1 \pm 0.11^{*}$ & $1.35 \pm 0.07$ \\
\hline Triglycerides & $\mathrm{mg} / \mathrm{dl}$ & $1.4 \pm 0.21$ & $0.85 \pm 0.11 * *$ & $0.91 \pm 0.22 *$ & $1.54 \pm 0.21$ & $0.96 \pm 0.16 * *$ & $1.18 \pm 0.3$ \\
\hline Urea & $\mathrm{mg} / \mathrm{dl}$ & $0.52 \pm 0.14$ & $0.38 \pm 0.06$ & $0.45 \pm 0.2$ & $0.44 \pm 0.11$ & $0.48 \pm 0.06$ & $0.60 \pm 0.00$ \\
\hline Creatinine & $\mathrm{mg} / \mathrm{dl}$ & $0.30 \pm 0.02$ & $0.32 \pm 0.02$ & $0.31 \pm 0.03$ & $0.38 \pm 0.01$ & $0.35 \pm 0.03$ & $0.40 \pm 0.02$ \\
\hline AST & $\mathrm{IU} / 1$ & $265.5 \pm 103$ & $135.25 \pm 39$ & $148.75 \pm 24.5$ & $138.67 \pm 7.51$ & $201.4 \pm 55.4$ & $216 \pm 60.81$ \\
\hline ALT & $\mathrm{IU} / 1$ & $93 \pm 21.2$ & $61.75 \pm 11.2 *$ & $67.75 \pm 4.2$ & $77 \pm 3.61$ & $85.2 \pm 34.24$ & $107 \pm 39.6$ \\
\hline ALP & $\mathrm{IU} / 1$ & $63.8 \pm 5.11$ & $61.8 \pm 4.43$ & $60.25 \pm 1.89$ & $66 \pm 3$ & $65.2 \pm 6.46$ & $63 \pm 5.66$ \\
\hline CPK & IU/1 & $32 \pm 2.8$ & $34 \pm 3.3$ & $31.5 \pm 3.08$ & $27 \pm 4.2$ & $33 \pm 2.1$ & $31.1 \pm 2.4$ \\
\hline Uric acid & $\mathrm{mg} / \mathrm{dl}$ & $97.2 \pm 8.8$ & $88.4 \pm 11.33$ & $66 \pm 19.16^{*}$ & $108 \pm 6.56$ & $108.2 \pm 7.85$ & $100.5 \pm 0.71$ \\
\hline Total proteins & $\mathrm{g} / \mathrm{dl}$ & $52.82 \pm 7.11$ & $50.84 \pm 3.55$ & $49.78 \pm 2.5$ & $47.8 \pm 4.1$ & $47.66 \pm 4.26$ & $52.95 \pm 2.9$ \\
\hline Albumin & $\mathrm{g} / \mathrm{dl}$ & $34.31 \pm 3.1$ & $37.34 \pm 2.31$ & $33.17 \pm 3.93$ & $30.46 \pm 0.24$ & $33.03 \pm 2.47$ & $33.98 \pm 1.68 *$ \\
\hline$\gamma-\mathrm{GT}$ & $\mathrm{IU} / 1$ & $5.18 \pm 1.36$ & $4.16 \pm 0.99$ & $5.33 \pm 1.12$ & $4.63 \pm 1.7$ & $4.12 \pm 0.9$ & $4.05 \pm 0.21$ \\
\hline Calcium & $\mathrm{mEq} / \mathrm{l}$ & $93.8 \pm 17.23$ & $95.6 \pm 6.27$ & $100.75 \pm 4.5$ & $93 \pm 1$ & $92.5 \pm 1.82$ & $101.5 \pm 3.54 *$ \\
\hline Sodium & $\mathrm{mEq} / \mathrm{l}$ & $129.4 \pm 1.5$ & $126.6 \pm 4.3$ & $128.75 \pm 1.5$ & $131.67 \pm 2.52$ & $131 \pm 3.31$ & $126.5 \pm 0.71$ \\
\hline Potassium & $\mathrm{mEq} / 1$ & $3.12 \pm 0.38$ & $3.18 \pm 0.8$ & $3.18 \pm 0.22$ & $3.7 \pm 0.17$ & $2.8 \pm 0.66$ & $2.3 \pm 0.28$ \\
\hline Chloride & $\mathrm{mEq} / \mathrm{l}$ & $80.6 \pm 2.7$ & $82.6 \pm 5.22$ & $84.25 \pm 4.78$ & $82.33 \pm 2.52$ & $84.2 \pm 5.17$ & $85 \pm 1.41$ \\
\hline LDH & $\mathrm{IU} / 1$ & $112 \pm 16$ & $116 \pm 12.3$ & $106.5 \pm 6.45$ & $110.33 \pm 11.15$ & $119 \pm 10.68$ & $127.5 \pm 4.95$ \\
\hline Total bilirubin & $\mathrm{mg} / \mathrm{l}$ & $18.2 \pm 2.28$ & $15.2 \pm 2.5$ & $17.5 \pm 2.51$ & $15.33 \pm 2.08$ & $18 \pm 2.24$ & $20 \pm 0.8$ \\
\hline
\end{tabular}

Significantly different from the control group at the level of $\mathrm{p}<0.05(*)$ or $\mathrm{p}<0.01(* *)$. ALT $=$ Alanine aminotransferase, AST $=$ Aspartate aminotransferase, $\gamma$-GT $=$ Gamma glutamyl transpeptidase, $\mathrm{LDH}=$ Lactate dehydrogenase; CPK $=$ creatine phosphate kinase, ALP $=$ alkaline phosphatase. Significant difference explained by $* \mathrm{p}<0.05 ; * * \mathrm{p}<0.01$. 
In conclusion, the present study revealed that methanol extract of $T$. glaucesens leaves did not pose adverse effects at single high dose $(2500 \mathrm{mg} / \mathrm{kg}$ bw) oral administration in mice. Thus, the DL50 was higher than $2500 \mathrm{mg} / \mathrm{kg}$ bw recommended during the screening of plant toxicity. For repetitive study, the methanol extract of $T$. glaucesens leaves have been found to cause benefit effects at therapeutic dose $(13.90 \mathrm{mg} / \mathrm{kg} \mathrm{bw} /$ day) used in traditional medicine in Côte d'Ivoire against malaria. Thus, weight gain, hypolipidemic actions, hepatoprotection and hemoglobin increasing have been observed. Moreover, the multiple of 100 of therapeutic dose $(13.90 \mathrm{mg} / \mathrm{kg} \mathrm{bw} /$ day $)$ remained relatively bio-tolerated by animals excepted to leucopenia and low hemoglobin levels observed. Taken together, our results suggested the NOAEL of $T$. glaucesens leaves extract could be near but under $1390 \mathrm{mg} / \mathrm{kg}$ bw/ day.

\section{Acknowledgements}

This research was partially funded by an African Doctoral Dissertation Research Fellowship award offered by the African Population and Health Research Center (APHRC) in partnership with the International Development Research Centre (IDRC) and the PASRES (Programme d'Appui Stratégique à la REcherche Scientifique en Côte d'Ivoire).

\section{References}

[1] E. Nasir and S. I. Ali, "Flora of West Pakistan”, No. 122, vol. 1. Ferozsons Karachi, 1978.

[2] A. Dermarderosian, "The Review of Natural Products I", Facts and Comparison, Missouri, pp. 637, 2002.

[3] J. Koudou, G. Roblot and R. Wylde, "Tannin Constituents of Terminalia glaucescens", Planta Med. 1995, vol. 61, pp. 490.

[4] E. O. Sote and M. Wilson, "In-vitro antibacterial effects of extracts of Nigerian tooth-cleaning sticks on periodontopathic bacteria", Afr. Dent. J., 1995, vol. 9, pp.15-19.

[5] A. Mustofa, F. Valentin, Y. Benoit-Vical, D. Pelissier, M. Kone-Bamba and J. Mallie, "Antiplasmodial activity of plant extracts used in west African traditional medicine", Ethnopharmacol., 2000, vol. 73, pp.145-151.

[6] Y. H. Choi, J. M. Pezzuto, A. D. Kinghorn and N. R. Farnsworth, "Ellagic acid derivatives of Agrostistachys hookeri”, Planta Med., 1988, vol. 54, pp.511-513.

[7] S. Terashima, M. Schimizu, H. Nakayama, M. Ishikura, A. Suzui and N. Morita, "Studies on aldose reductase inhibitors from medicinal plant of "sinfito," Potentilla candicans, and further synthesis of their related compounds", Chem. Pharm. Bull., 1990, Vol. 38, pp. 2733-2736.
[8] D. E. U. Ekong and O. G. Idemudia, "Constituents of some West African members of the genus Terminalia", J. Chem. Soc. C., 1967, pp. 863-864.

[9] E.N. Bum, S. Soudi, E.R. Ayissi, C. Dong, N.H. Lakoulo, F. Maidawa, P.F.E. Seke, L.D. Nanga, G.S. Taiwe, T. Dimo, N. Njikam, A. Rakotonirina, S.V. Rakotonirina, A. Kamanyi "Anxiolytic Activity Evaluation of Four Medicinal Plants from Cameroon" African Journal of Traditional, Complementary and Alternative Medicines, 2011, Vol 8, pp. 130-139.

[10] O.O Ayepola, "Evaluation of the Antimicrobial Activity of Root and Leaf Extracts of Terminalia glaucescens" Advances in Natural and Applied Sciences, 2009, vol. 3, pp. 188-191.

[11] G. Ingabire, H.K. Koumaglo, C. De Souza, C.K. Dotse, K. Anani, J. Kabera, et al. Antimicrobial activity and preliminary phytochemical screening of Turraea heterophylla and Terminalia glaucescens used in Togo ethnomedecine to treat common infections. Planta Med., 2007, vol. 73, pp. 986-996.

[12] A.M. Oloyede, A. O. Efem, I. K. Ejikeme, "Evaluation of the antimicrobial and phytochemical properties of a herbal preparation”, Nature \& Science, 2012, Vol. 10, pp. 43-48.

[13] Atta-ur-Rahman, Seema Zareen, M. Iqbal Choudhary, M. Nadeem Akhtar, Shahida Shujaat, and F. N. Ngounou, "Some Chemical Constituents of Terminalia glaucescens and their Enzymes Inhibition Activity”, Z. Naturforsch., 2005, vol. 60, pp. $347-350$.

[14] G. B. Sabas Nya Njomen, R. Kamgang, J.L.E. Oyono and N. Njikam "Antioxidant potential of the methanol-methylene chloride extract of Terminalia glaucescens leaves on mice liver in streptozotocin-induced stress", Indian J Pharmacol., 2008, vol. 40, pp. 266-270.

[15] H.S. Kim, S.J. Kwack, E.S. Han, T.S. Kang, S.H. Kim, S.Y. Han, "Induction of apoptosis and CYP4A1 expression in Sprague-Dawley rats exposed to low doses of perfluorooctane sulfonate" The Journal of Toxicological Sciences, 2011, Vol. 36, pp. 201-210.

[16] M.S. Kaiya and S.M.Thansborg, "Effect of Acacia nilotica and Acacia karoo diets on haemonchus contortus in goats", Vet Parasitol, 2003, vol.115, pp. 265-72.

[17] W. Vincent "The Etiology and Management of Leukopenia", Can Fam Physician, 1984, vol.30, pp. 1835-1839.

[18] J.F. Kiraly and M.S. Wheby, "Bone marrow necrosis", The American Journal of Medicine, 1976, Vol. 60, pp. 361-368.

[19] Semra Paydas, Melek Ergin, Fikri Baslamisli, Sinan Yavuz, Suzan Zorludemir, Berksoy Sahin, Filiz A. Bolat Bone marrow necrosis: Clinicopathologic analysis of 20 cases and review of the literature American Journal of Hematology, 2002, Vol. 70, pp. 300-305.

[20] M. W. Yeh, P. H. G. Ituarte, H. C. Zhou, S. Nishimoto, I.-L. Amy Liu, A. Harari, P. I. Haigh and A. L. Adams, "Incidence and Prevalence of Primary Hyperparathyroidism in a Racially Mixed Population", Journal of Clinical Endocrinology \& Metabolism, 2013, vol.10, pp. 4022. 